\title{
ANALISIS VOLUME TAMPUNGAN KOLAM RETENSI DAS DELI SEBAGAI SALAH SATU UPAYA PENGENDALIAN BANJIR KOTA MEDAN
}

\author{
Asril Zevri \\ Dosen Pengajar Program Studi Teknik Sipil, Fakultas Teknik, UMSU, Medan \\ Surel : Asrilzevri19@gmail.com \\ Diterima : 26 November 2017; Disetujui : 30 November 2017
}

\begin{abstract}
ABSTRAK
Daerah Aliran Sungai Deli adalah salah satu DAS yang berperan penting terhadap Kota Medan. Curah hujan yang tinggi disertai dengan perubahan tata guna lahan dapat meningkatkan limpasan air permukaan mengalir dengan cepat dan menimbulkan debit banjir. Tujuan dari penelitian ini untuk menganalisa volume tampungan kolam retensi akibat debit banjir kala ulang DAS Deli dengan debit kapasitas penampang sungainya. Lingkup kegiatan dalam penelitian ini yaitu menganalisa curah hujan harian maksimum rata-rata DAS Deli, curah hujan harian maksimum kala ulang 2 s/d 100 tahun, debit banjir kala ulang 2 s/d 100 tahun, debit kolam retensi, dan volume tampungan kolam retensi. Hasil studi menunjukan debit kolam retensi $388.66 \mathrm{~m}^{3} / \mathrm{det}$ terjadi dengan lama waktu banjir 6.13 jam sehingga volume tampungan kolam retensi mencapai 8,600,000 $\mathrm{m}^{3}$ dengan rencana luas lahan 215 ha dan rata-rata kedalaman 4 meter.
\end{abstract}

Kata Kunci : debit banjir, das deli, kota medan, peengendalian banjir, kolam retensi.

\section{Pendahuluan}

Daerah Aliran Sungai Deli merupakan salah satu daerah aliran yang berada di dalam cakupan Wilayah Satuan Belawan Ular Padang. Luas catchment area Daerah Aliran Sungai Deli mencapai 47,748.01 Ha dengan panjang sungai mencapai $70 \mathrm{~km}$ dari hulu ke hilir. Hulu DAS Sungai Deli berada di Kabupaten Deli Serdang yaitu Sibolangit dan Kutalimbaru yang mengalir ke hilir melewati jantung Kota Medan dan bermuara di Selat Malaka.

Curah hujan yang tinggi disertai dengan kondisi sungai yang mengalami pendangkalan akibat erosi dan sedimentasi mengakibatkan kapasitas tampungan sungai dalam menampung limpasan debit banjir tidak maksimal. Kondisi ini dapat mengakibatkan volume air meluap sehingga terjadi daerah genangan banjir.

Potensi banjir di Daerah Aliran Sungai Deli dapat memberikan dampak yang buruk terhadap penduduk di Kota Medan. Tinggi muka air banjir akibat debit banjir DAS Deli mencapai 1-3 meter dari dataran sungai yang menggenangi Kota Medan (Zevri, 2014). Kondisi banjir ini akan tetap terjadi dikarenakan perubahan tata guna lahan dan belum adanya sistem penanggulangan banjir di Kota Medan yang efektif dan efisien.
Salah satu upaya metode pengendalian banjir secara struktural yaitu dengan merencanakan kolam retensi. Pendekatan dalam merencanakan kolam retensi yaitu dengan memahami karakteristik curah hujan, debit banjir, tata guna lahan, dan penampang sungai. Parameter tersebut dapat menjadi dasar dalam merencanakan volume tampungan kolam retensi yang berkelanjutan dan berwawasan lingkungan.

\section{Kajian Pustaka}

\subsection{Potensi Bnjir dan olam Retensi}

Banjir adalah suatu kondisi di mana tidak tertampungnya air dalam saluran pembuang (palung sungai) atau terhambatnya aliran air di dalam saluran pembuang, sehingga meluap menggenangi daerah dataran banjir di sekitarnya (Hasibuan, 2004). Menurut hasil studi dan analisis JICA (1992) menyatakan bahwa kapasitas penampang Sungai Deli yang ada pada saat ini (natural) hanya mampu menampung debit di bagian hulu Qhulu $=160 \mathrm{~m}^{3} /$ det, Qtengah $=$ $269 \mathrm{~m}^{3} /$ det, dan Qhilir $=341 \mathrm{~m}^{3} /$ det (Ginting, 2012). Debit kapasitas Sungai Deli di tiap bagian penampang ditampilkan pada Gambar 1. 


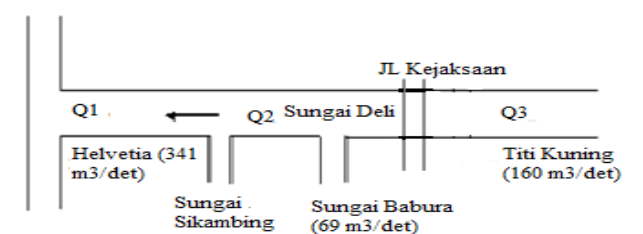

Gambar 1. Perkiraan Debit Kapasitas Sungai Deli

Perkiraan debit banjir Sungai Deli pada beberapa ruas (section) untuk berbagai periode ulang menurut hasil analisis yang dilaporkan pada study JICA (1992) adalah seperti diperlihatkan pada Tabel 1.

Tabel 1. Perkiraan Debit Banjir untuk Periode Ulang Sungai Deli

\begin{tabular}{cccccc}
\hline \multirow{2}{*}{$\begin{array}{c}\text { Debit } \\
\text { Banjir } \\
\text { (m3/det) }\end{array}$} & \multicolumn{5}{c}{ Periode Ulang (Tahun) } \\
\cline { 2 - 6 } & $\mathbf{1 0}$ & $\mathbf{2 0}$ & $\mathbf{3 0}$ & $\mathbf{5 0}$ & $\mathbf{1 0 0}$ \\
\hline $\mathrm{Q}_{1}$ & 460 & 530 & 570 & 620 & 690 \\
\hline $\mathrm{Q}_{2}$ & 420 & 490 & 520 & 570 & 640 \\
\hline $\mathrm{Q}_{3}$ & 260 & 300 & 320 & 340 & 380 \\
\hline
\end{tabular}

Dari hasil analisis di atas dapat dilihat bahwa debit banjir Sungai Deli pada bagian yang belum dinormalisasi yakni antara JL. Kejaksaan dan titi kuning untuk periode 10 tahun adalah sebesar $\mathrm{Q}_{3}=260 \mathrm{~m}^{3} /$ det dibandingkan dengan kapasitas penampang pada bagian ini yakni 160 $\mathrm{m}^{3} /$ det, maka pada kejadian banjir periode ulang 10 tahun akan terjadi potensi banjir yang mengancam permukiman penduduk sebesar $100 \mathrm{~m}^{3} /$ det. Limpasan debit banjir kala ulang $100 \mathrm{~m}^{3} /$ det dapat diatasi salah satunya dengan perencanaan kolam retensi. Kolam retensi adalah kolam yang berfungsi untuk menampung air hujan sementara waktu dengan memberikan kesempatan untuk dapat meresap ke dalam tanah yang operasionalnya dapat dikombinasikan dengan pompa atau pintu air (Kementerian PU Cipta Karya, 2010). Fungsi dari kolam retensi adalah untuk menggantikan peran lahan resapan yang dijadikan lahan tertutup/perumahan/perkantoran maka fungsi resapan dapat digantikan dengan kolam retensi. Fungsi kolam ini adalah menampung air hujan langsung dan aliran dari sistem untuk diresapkan ke dalam tanah dan kemudian dapat dimanfaatkan untuk kebutuhan air.

\section{Metodologi}

Lokasi penelitian berada di DAS Deli dengan luas 47,748.01 Ha. Daerah Aliran Sungai Deli terbentang antara $3^{\circ} 13^{\prime} 35,50^{\prime \prime} \mathrm{s} / \mathrm{d} 3^{\circ} 47^{\prime} 06,05^{\prime \prime}$ garis Lintang Utara dan meridian $98^{\circ} 29^{\prime}$ 22,52" s/d 98 42' 51,23" Bujur Timur. Secara administrasi DAS Deli berada pada 3 (tiga) Kabupaten yaitu Karo 1,417.65 Нa (3 \%), Kabupaten Deli Serdang seluas 29,115.20 Ha $(61.56 \%)$ dan Kota Medan seluas 16,765.16 ha (35.45\%) ditampilkan pada Gambar 2.

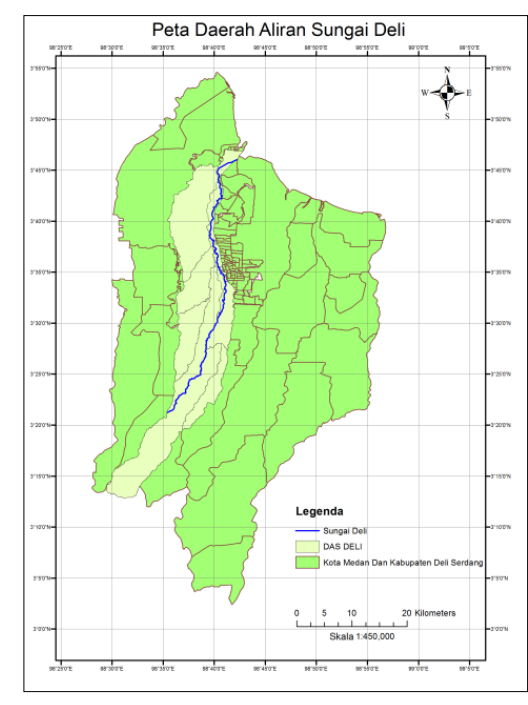

Gambar 2. Lokasi Penelitian

Penelitian dilakukan secara eksploratif, kuantitatif, dan kualitatif. Artinya data-data penelitian diperoleh secara kuantitatif menggunakan persamaan-persamaan yang relevan dan hasilnya dijelaskan secara kualitatif. Kemudian kesimpulan diambil secara induktif yang artinya poin-poin pengamatan lapangan dan analisa data akan menghasilkan potensi volume kolam retensi yang ditampilkan pada Gambar 3

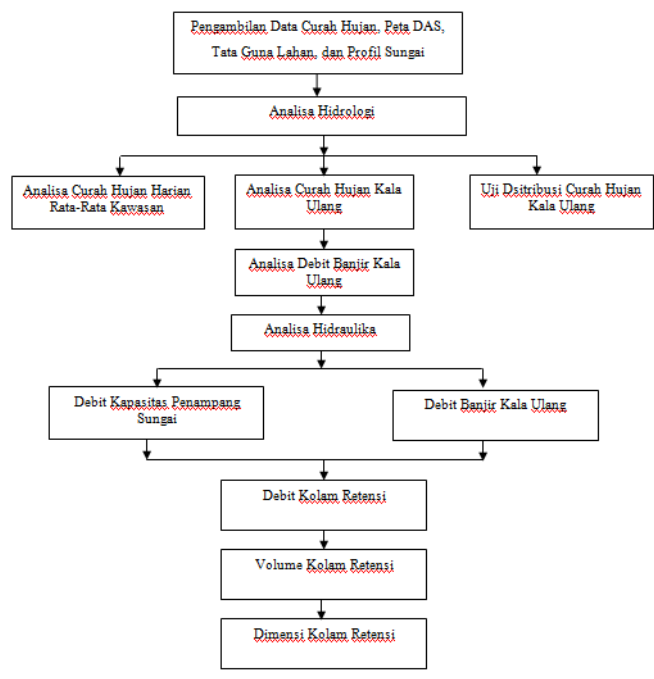

Gambar 3. Ruang Lingkup Penelitian 


\section{Hasil dan Pembahasan}

\subsection{Analisis Hidrologi}

Analisa hidrologi dalam penelitian ini yaitu menghitung curah hujan harian maksimum rata-rata kawasan di DAS Deli dengan metode polygon thiessen. Stasiun penakar curah hujan dipilih berdasarkan titik stasiun yang dapat mewakili bagian hulu, tengah, dan hilir DAS Deli. Polygon thiessen DAS Deli ditampilkan pada Gambar 4.

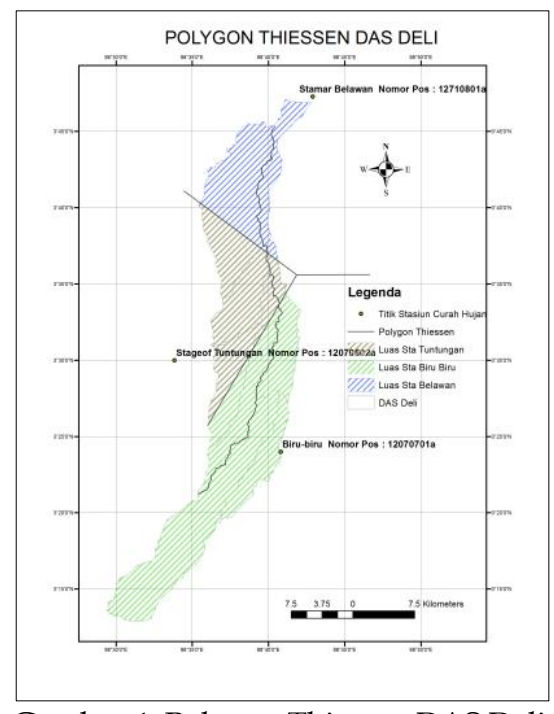

Gambar 4. Polygon Thiessen DAS Deli

Hasil analisa polygon thiessen stasiun curah hujan terhadap DAS Deli ditampilkan pada Tabel 2.

Tabel 2. Hasil Analisa Polygon Thiessen DAS Deli

\begin{tabular}{ccc}
\hline Stasiun & Luas $\mathbf{( k m 2 )}$ & $\begin{array}{c}\text { Faktor } \\
\text { Thiessen }\end{array}$ \\
\hline A Belawan & 102.44 & 0.21 \\
\hline A Biru Biru & 254.32 & 0.53 \\
\hline A Tuntungan & 120.72 & 0.25 \\
\hline Total & 477.48 & 1 \\
\hline
\end{tabular}

Sehingga analisa curah hujan rata-rata harian maksimum kawasan DAS Deli ditampilkan pada Tabel 3.

Tabel 3. Hasil Analisa Curah Hujan Harian Rata-Rata Maksimum DAS Deli

\begin{tabular}{cccccccc}
\hline 2010 & 100 & 0.53 & 125 & 0.21 & 128 & 0.25 & 112.41 \\
\hline 2011 & 83 & 0.53 & 132 & 0.21 & 106 & 0.25 & 99.30 \\
\hline 2012 & 111 & 0.53 & 120 & 0.21 & 104 & 0.25 & 111.13 \\
\hline 2013 & 108 & 0.53 & 115 & 0.21 & 89 & 0.25 & 104.67 \\
\hline 2014 & 143 & 0.53 & 103 & 0.21 & 87 & 0.25 & 120.23 \\
\hline 2015 & 122 & 0.53 & 96 & 0.21 & 83 & 0.25 & 106.54 \\
\hline
\end{tabular}

Hasil analisa menjelaskan bahwasanya curah hujan rata-rata harian maksimum di kawasan DAS Deli berada di antara $99.30 \mathrm{~mm} \mathrm{~s} / \mathrm{d} 176.20$ $\mathrm{mm}$. Perhitungan curah hujan periode kala ulang dilakukan dengan analisis statistik (distribusi frekuensi) yaitu metode gumbel, normal, log normal dan log pearson. Metode tersebut bertujuan untuk memprediksi besarnya curah hujan kala ulang yang terjadi dalam jangka waktu periode kala ulang $2 \mathrm{~s} / \mathrm{d}$ 100 tahun. Analisa curah hujan kala ulang ditampilkan pada Tabel 4.

Tabel 4. Hasil Analisa Curah Hujan Kala Ulang DAS Deli

\begin{tabular}{|c|c|c|c|c|c|c|c|c|}
\hline \multirow{2}{*}{$\begin{array}{c}\text { Jenis } \\
\text { Sebaran }\end{array}$} & \multicolumn{3}{|c|}{ Syarat } & \multicolumn{3}{|c|}{$\begin{array}{c}\text { Hasil } \\
\text { Perhitungan }\end{array}$} & \multicolumn{2}{|c|}{ Perbandingan } \\
\hline & Cs & Ck & $\mathrm{Cv}$ & Cs & $\mathbf{C k}$ & $\mathrm{Cv}$ & Cs & Ck \\
\hline $\begin{array}{l}\text { Normal } \\
\text { (Gauss) }\end{array}$ & $=0$ & - & $=3$ & 1.65 & 4.81 & 0.18 & $\begin{array}{c}\text { Tidak } \\
\text { Me } \\
\text { menuhi }\end{array}$ & $\begin{array}{c}\text { Tidak } \\
\text { Me } \\
\text { menuhi }\end{array}$ \\
\hline $\begin{array}{c}\text { Log } \\
\text { Normal }\end{array}$ & $=3 \mathrm{Cv}$ & - & $=0.6$ & 0.55 & 4.81 & 0.18 & $\begin{array}{c}\text { Tidak } \\
\text { Me } \\
\text { menuhi }\end{array}$ & $\begin{array}{c}\text { Tidak } \\
\text { Me } \\
\text { menuhi }\end{array}$ \\
\hline $\begin{array}{c}\text { Log } \\
\text { Pearson } \\
\text { III }\end{array}$ & $\neq 0$ & - & $\neq 0$ & 1.65 & 4.81 & 0.18 & $\begin{array}{c}\mathrm{Me} \\
\text { menuhi }\end{array}$ & $\begin{array}{c}\mathrm{Me} \\
\text { menuhi }\end{array}$ \\
\hline Gumbel & $\begin{array}{c}< \\
1.1396\end{array}$ & $\begin{array}{c}< \\
5.4002\end{array}$ & - & 1.65 & 4.81 & 0.18 & $\begin{array}{c}\text { Tidak } \\
\text { Me } \\
\text { menuhi }\end{array}$ & $\begin{array}{c}\mathrm{Me} \\
\text { menuhi }\end{array}$ \\
\hline
\end{tabular}

Uji distribusi parameter statistik menunjukan bahwasanya curah hujan kala ulang dengan metode Log Pearson III adalah yang terpilih dan memenuhi syarat. Curah hujan kala ulang dengan metode Log Pearson III digunakan untuk menghitung debit banjir dengan metode HSS Nakayasu. Analisa debit banjir dibagi menjadi 3 section yaitu section bagian hulu, tengah, dan hilir. Pembagian section bertujuan untuk dapat menganalisa selisih antara debit banjir dengan debit kapasitas sungai sehingga hasil selisih dari kedua debit tersebut dapat menjadi dasar dalam menganalisa volume tampungan kolam retensi. Hasil analisa debit banjir kala ulang tiap section ditampilkan pada

\begin{tabular}{cccccccc}
\hline Tahun & $\begin{array}{c}\text { Biru } \\
\text { Biru }\end{array}$ & $\begin{array}{c}\text { Faktor } \\
\text { Thiessen }\end{array}$ & $\begin{array}{c}\text { Bela } \\
\text { wan }\end{array}$ & $\begin{array}{c}\text { Faktor } \\
\text { Thiessen }\end{array}$ & $\begin{array}{c}\text { Tun } \\
\text { tungan }\end{array}$ & $\begin{array}{c}\text { Faktor } \\
\text { Thiessen }\end{array}$ & $\begin{array}{c}\text { Rata } \\
\text { Ratab }\end{array}$ \\
\hline 2006 & 148 & 0.53 & 196 & 0.21 & 219 & 0.25 & 176.20 \\
\hline 2007 & 101 & 0.53 & 185 & 0.21 & 169 & 0.25 & 136.17 \\
\hline 2008 & 108 & 0.53 & 172 & 0.21 & 159 & 0.25 & 134.58 \\
\hline 2009 & 100 & 0.53 & 158 & 0.21 & 140 & 0.25 & 122.52 \\
\hline
\end{tabular}


Tabel 5. Hasil Analisa Debit Banjir Kala Ulang Tiap Section

\begin{tabular}{|c|c|c|c|c|c|c|}
\hline \multirow{2}{*}{ Section } & \multicolumn{7}{c|}{ Debit Banjir Kala Ulang (Tahun) } \\
\cline { 2 - 7 } & $\mathbf{2}$ & $\mathbf{5}$ & $\mathbf{1 0}$ & $\mathbf{2 5}$ & $\mathbf{5 0}$ & $\mathbf{1 0 0}$ \\
\hline Titi Kuning (Q3) & 370.16 & 375.46 & 468.02 & 503.55 & 526.94 & 548.66 \\
\hline Junction S. Deli- & & & & & & \\
\hline Babura (Q2) & 380.78 & 386.22 & 481.44 & 517.99 & 542.05 & 564.40 \\
\hline Hilir (Q1) & 385.83 & 391.35 & 487.83 & 524.86 & 549.24 & 571.88 \\
\hline
\end{tabular}

Hasil analisa debit banjir kala ulang dengan metode HSS Nakayasu menjelaskan bahwasanya debit banjir memiliki potensi banjir yang dapat mengakibatkan daerah genangan banjir.

\subsection{Analisa Hidraulika}

Analisa hidraulika bertujuan untuk mengetahui potensi debit kolam retensi yang dihitung berdasarkan hasil selisih antara debit banjir kala ulang dengan debit kapasitas tiap penampang sungai (Astuti \& Florince, 2015). Debit banjir kala ulang mempunyai hubungan dengan waktu puncak banjir artinya curah hujan yang jatuh ke luasan DAS dengan intensitas curah hujan yang tinggi dari titik awal sampai titik tinjauan mengakibatkan waktu normal berubah menjadi waktu puncak banjir. Lama waktu puncak banjir menjadi dasar dalam menganalisa volume kolam retensi sehingga besarnya debit kolam retensi yang mengalir dapat ditampung dengan rencana dimensi volume kolam (Amin, 2016). Hasil analisa debit kolam retensi ditampilkan pada Tabel 6.

Tabel 6. Hasil Analisa Debit Kolam Retensi Kala Ulang Tiap Section

\begin{tabular}{|c|c|c|c|c|c|c|}
\hline \multirow{2}{*}{ Section } & \multicolumn{6}{|c|}{ Debit Banjir Kala Ulang (Tahun) } \\
\hline & 2 & 5 & 10 & 25 & 50 & 100 \\
\hline Titi Kuning (Q3) & 370.16 & 375.46 & 468.02 & 503.55 & 526.94 & 548.66 \\
\hline Q3 (Kapasitas Penampang) & 160.00 & 160.00 & 160.00 & 160.00 & 160.00 & 160.00 \\
\hline Q Kolam Retensi & 210.16 & 215.46 & 305.02 & 343.55 & 366.94 & 388.66 \\
\hline Junction S. Deli-Babura (Q2) & 380.78 & 386.22 & 481.44 & 517.99 & 542.05 & 564.40 \\
\hline Q2 (Kapasitas Penampang) & 229.00 & 229.00 & 229.00 & 229.00 & 229.00 & 229.00 \\
\hline Q Kolam Retensi & 151.78 & 157.22 & 252.44 & 288.99 & 313.05 & 335.40 \\
\hline Hilir (Q1) & 385.83 & 391.35 & 487.83 & 524.86 & 549.24 & 571.88 \\
\hline Q1 (Kapasitas Penampang) & 446.00 & 446.00 & 446.00 & 446.00 & 446.00 & 446.00 \\
\hline Q Kolam Retensi & -60.17 & -54.65 & 41.83 & 78.86 & 103.24 & $125.8 \mathrm{~s}$ \\
\hline
\end{tabular}

Hasil analisa diperoleh bahwasanya debit kolam retensi yang maksimum berada di bagian hulu yaitu Qtampungan kolam $=388.66$ $\mathrm{m}^{3} /$ det. Waktu awal banjir yaitu $\mathrm{Tg}=2.36$ jam, puncak banjir $\mathrm{Tp}=3.69 \mathrm{Jam}$, dan normal $\mathrm{Tr}=$ $8.42 \mathrm{Jam}$. Hubungan antara Debit banjir dengan waktu aliran dapat ditampilkan pada Gambar 5

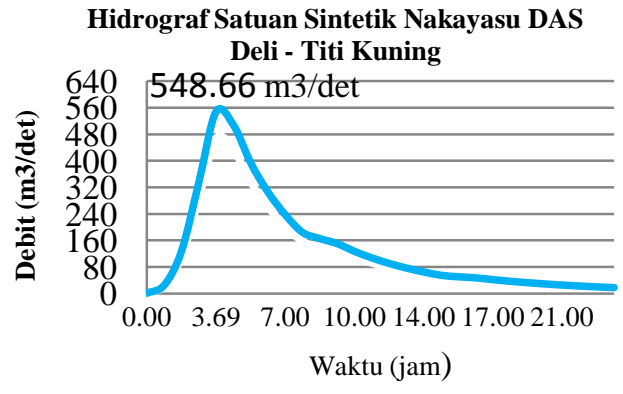

Gambar 5. Grafik HSS Nakayasu Debit Banjir Kala Ulang 100 Tahun DAS DeliTiti Kuning

Analisa volume kolam retensi yaitu:

Volume Kolam Retensi

$=\mathrm{Q}$ kolam retensi $\times$ (Waktu Normal-Waktu Awal Banjir)

$=388.66 \mathrm{~m}^{3} / \operatorname{det} \times(8.49-2.36) \mathrm{jam}$

$=366.66 \mathrm{~m}^{3} /$ det $\times 6.13 \times 3600$ detik

$=8,576,948.88 \mathrm{~m}^{3} . \approx 8.600 .000 \mathrm{~m}^{3}$

Hasil di atas dapat dijadikan dasar dalam merencanakan dimensi volume kolam retensi yang ditampilkan di bawah ini.

$$
\begin{aligned}
\text { Dimensi Kolam Retensi } & =\mathrm{A} \times \mathrm{T} \\
& =2.150 .000 \mathrm{~m}^{2} \times 4 \mathrm{~m} \\
& =8,600,000 \mathrm{~m}^{3} .
\end{aligned}
$$

Dalam perencanaan volume kolam retensi diperlukan luas lahan 215 ha dengan kedalaman rata-rata 4 meter. Alokasi debit banjir terhadap perencanaan kolam retensi sebagai pengendalian banjir ditampilkan pada Gambar 6.

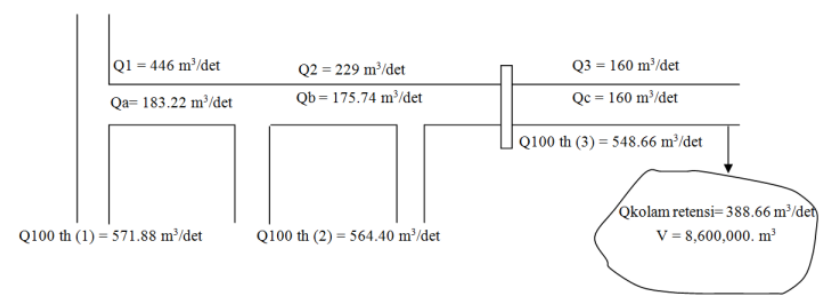

Gambar 6. Alokasi Debit Banjir Terhadap Debit Kapasitas Sungai Setelah Pembangunan Kolam Retensi

\section{Simpulan}

Berdasarkan data curah hujan harian maksimum, tata guna lahan, karakteristik profil sungai diperoleh bahwasanya debit banjir kala ulang 100 tahun DAS Deli-Titi Kuning memilki potensi banjir terhadap debit kapasitas 
penampang sungai. Debit banjir kala ulang 100 tahun DAS Deli-Titi Kuning Q100 = 548.66 $\mathrm{m}^{3} /$ det sementara debit kapasitas penampang sungai Deli-Titi Kuning Qkapasitas $=160$ $\mathrm{m}^{3} /$ det sehingga mengakibatkan debit kolam retensi $=388.66 \mathrm{~m}^{3} /$ det dengan lama waktu puncak banjir kembali ke waktu normal terjadi dalam jangka waktu 6.13 jam. Potensi Volume tampungan kolam retensi yaitu 8,600,000 $\mathrm{m}^{3}$ sehingga rencana dimensi kolam retensi membutuhkan luas lahan $215 \mathrm{Ha}$ dengan kedalaman rata-rata 4 meter.

\section{Daftar Pustaka}

BAmin, M. (2016). Analisis Genangan Banjir di Kawasan Sekitar Kolam Retensi dan Rencana Pengendaliannya, Studi Kasus: Kolam Retensi Siti Khadijah Palembang. Jurnal Perencanaan Wilayah Dan Kota, Volume 2, No 2.

Astuti, D. dkk. (2015). Analisis kolam retensi sebagai pengendalian banjir Genangan di kecamatan payung sekaki. JOMFTEKNIK, Volume 3, No 1.

Direktorat Jendral Cipta Karya. (2010). Tata Cara Pembuatan Kolam Retensi dan Polder. Jakarta: Departemen Pekerjaan Umum.

Florince, F. dkk. (2015). Studi Kolam Retensi sebagai Upaya Pengendalian Banjir Sungai Way Simpur Kelurahan Palapa Kecamatan Tanjung Karang Pusat. JRSDD, Volume 3, Hal: 507520.

Ginting, M. (2012). Studi Potensi dan Mitigasi Banjir Kota Medan. Prosiding Seminar Nasional-1 BMPTTSSI USU, Medan.

Hasibuan, G. M .(2004). Model koordinasi kelembagaan pengelolaan banjir perkotaan terpadu. Disertasi Perencanaan Wilayah USU. Medan.

JICA, Main Report. (1992). The Study On Belawan Padang Integrated River Basin Development, Medan.

Zevri, A. (2014). Analisis Potensi Resiko Banjir pada DAS yang Mencakup Kota Medan dengan Sistem Informasi Geografis. Tesis Master Prodi S2 Teknik Sipil USU 